\title{
Videogames e cultura colaborativa: a audiência como produtora de conteúdo em Beyond Good and Evil 2
}

DOI: https://doi.org/10.22409/pragmatizes.v10i19.40302

\section{Caio Túlio Olímpio Pereira da Costa ${ }^{1}$ Bruna Maria de Meneses ${ }^{2}$ Eduardo Duarte Gomes da Silva ${ }^{3}$}

Resumo: O trabalho pondera acercado engajamento de fãs a partir da observação do fandom de jogos da franquia Beyond Good and Evil. Com o primeiro título apresentado em 2003 e o segundo anunciado entre 2017 e 2018 , foram criados espaços online nos quais os fãs podem colaborar para a produção de conteúdo do novo jogo em diversos âmbitos, como artes e trilhas sonoras, os quais pretendemos versar a fim de analisar nuances do engajamento, apurando os tipos de cooperação oferecidas. A metodologia, que se utiliza de um levantamento bibliográfico acerca de cultura de fãs, conta com mapeamento do espectro de mecânicas colaborativas da produção, realizando estudo de caso do jogo. O jogador, nesse âmbito, se torna consumidor não apenas do produto final, mas, ao fazer parte do processo de criação, se vê mais próximo do seu objeto de adoração - o jogo -, criando vínculos fortes com o produto e com outros fãs a partir das trocas de experiências e ideias realizadas.

Palavras-chave: Fandom; Cultura da Participação; Games; Beyond Good and Evil.

Videojuegos y cultura colaborativa: la audiencia como productora de contenido en Beyond Good and Evil 2

Resumen: El artículo científico aborda elcompromiso de fans a través de laobservacióndelfandom de juegos de la franquia Beyond Good and Evil. Com suprimerotitulo presentado en 2003 y elsecondo anunciado entre 2017 y 2018, fueroncreadosespacios online en que fanspodrían colaborar conlaprodución de contenidodelnuevojuegoenvarios âmbitos, como arte y banda sonora, en que pretendemos analizarelcompromiso, determinando los tipos de cooperaciónofrecidos. La metodología utiliza una bibliografía sobre la cultura de losfans, conunmapeodel espectro de mecánicas de produción colaborativa, realizando un estúdio de caso deljuego. El jugador, en este contexto, se convierteen consumidor no solo delproducto final, pero, haciendo parte delproceso de creacion, esta

\footnotetext{
${ }^{1}$ Caio Túlio Olímpio Pereira da Costa. Mestrando em Comunicação pela Universidade Federal de Pernambuco (UFPE), Brasil. E-mail: caiotuliocosta3@gmail.com - https://orcid.org/0000-0002-72017157

${ }^{2}$ Bruna Maria de Meneses. Mestre em Comunicação pela Universidade Federal de Pernambuco (UFPE), Brasil. E-mail: 221bbruna@gmail.com - https://orcid.org/0000-0001-9395-4652

${ }^{3}$ Eduardo Duarte Gomes da Silva. Doutor em Ciências Sociais pela Pontifícia Universidade Católica de São Paulo (PUC-SP), Professor Associado do Dept. de Comunicação Social da Universidade Federal de Pernambuco (UFPE), Brasil. E-mail: edwartte@gmail.com - https://orcid.org/0000-00027272-0088
} 
cerca de su objeto de adoración - eljuego -, forjando fuertes vínculos conelproducto y conotrosfans al compartir experiencias e ideas.

Palabras clave: Fandom; Cultura de Participación; Games; Beyond Good and Evil.

Videogames and collaborative culture: the audience as content producer in Beyond Good and Evil 2

Abstract: The research considers the fan engagement through observation of the Beyond Good and Evil franchise and its fandom. With the first title released in 2003 and the second announced between 2017 and 2018, online communities emerged, in which fans could contribute with content production for the new game in distinct fields, such as art and soundtracks, being relevant to the research approach on the engagement, to explore the possible offered contributions. The methodology carried out a literature survey concerning fan culture, mapping the collaborative mechanics of production, considering it a case study. The player does not become only a consumer of the final product, however, while being part of the creation process, it gets closer to the beloved object - the game-, bonding with the product and other fans based on the experiences and ideas exchange.

Keywords: Fandom; Collaboration Culture; Games; Beyond Good and Evil.

\section{Videogames e cultura colaborativa: a audiência como produtora de conteúdo em Beyond Good and Evil 2}

\section{Introdução}

Em 2018 ocorreu a E3, a Electronic Entertainment Expo, aconvenção internacional realizada anualmente em que fabricantes, distribuidoras e desenvolvedoras de jogos eletrônicos apresentam seus novos produtos à imprensa especializada e fãs do segmento. Durante suas duas últimas edições, especificamente, foi introduzido ao mundo dos gamers o trailer do jogo Beyond Good and Evil 2. Com seu antecessor e primeiro título lançado em 2003, até o trailer de anúncio da sequência haviam se passado catorze anos de espera para os jogadores e admiradores da franquia. Durante esse tempo, muitos detalhes mudaram e se reinventaram no campo da tecnologia. Houve inovações na maneira como os jogos são desenvolvidos, recebidos pelo público e até mesmo jogados. Dentre as mudanças, aspectos técnicos também acompanharam esse quadro, como é o caso dos campos do design e roteiros. No entanto, o presente trabalho não tem como foco descrever as transformações sofridas pelos jogos eletrônicos, mas sim abordar as mudanças do ponto de vista de interação entre consumidores 
e produtores. Ou melhor, entre os fãs da franquia e os criadores de Beyond Good and Evil, levando em consideração aspectos de aproximação entre esses dois grupos graças ao advento da internet e da consequente mudança de papéis que a conexão em rede permite.

Entende-se que ao longo dos anos, tais transformações tecnológicas foram essenciais para reconfigurar as práticas de interação social. $\mathrm{Na}$ rede surgiram grupos de fãs, comunidades, espaços propícios para que se encontre pessoas com interesse semelhante e para que se interaja com elas. Ao mesmo tempo, as trocas também são possíveis em um nível expectador/consumidor-produto. Não é que aqueles que antes eram apenas jogadores subitamente passaram a criar em cima de jogos digitais, mas o aspecto de conexão e coletividade (JENKINS, 2009) permitiu que houvesse maior interação e engajamento. Ou seja, os jogadores, como audiência, podem ser vistos, ouvidos e entendidos tanto por outros jogadores quanto pelos criadores, em uma comunicação horizontal e menos hierarquizada, graças às diversas plataformas interacionais que o mundo globalizado permite. Quando Bailén (2009) traz apontamentos sobre a audiência no futuro, é dito que esta buscará acesso às experiências e recursos que alimentem sua existência psicológica, o que reforça o sentido de pertencimento. Quanto à participação, aqui significa dar sugestões, criar artes, músicas, vídeos e discutir conceitos relacionados ao universo dos jogos digitais, categorizando os participantes como verdadeiros agentes multimídia (CANCLINI, 2007) - os quais veremos mais detalhadamente no decorrer do trabalho.

Sendo assim, o que nos interessa refletir nesse artigo é a produção do jogo Beyond Good and Evil 2 a partirda cultura da participação em que o fandom ${ }^{4}$ é convocado a atuar. Vamos, em primeiro lugar, apresentar uma breve revisão bibliográfica que traz subsídios para que a compreensão acerca desse espectro da cultura da participação seja possível e justificável. Pretende-seainda uma pesquisa exploratória com intento de gerar familiarização com a temática. Em

\footnotetext{
${ }^{4}$ De acordo com Jenkins (2010), fandom se refere às estruturas sociais e práticas culturais criadas por consumidores da mídia de massa.
} 
segundo lugar serão abordadas exemplificações de mecânicas colaborativas que fazem jus ao contemporâneo potencial das audiências em relação às mídias que permeiam a sociedade conectada, trazendo conceituações que referenciam a sociabilidade. Em terceiro lugar, a partir de um estudo mais aprofundado sobre a construção e desenvolvimento colaborativo do jogo Beyond Good and Evil 2, optamos por estudo de caso. O estudo de caso é paraYin (2001, p. 32) uma "investigação empírica de um fenômeno contemporâneo dentro de um contexto da vida real".Goode e Hatt (1979, p. 421-422) observam que o estudo de caso "é um meio de organizar dados sociais preservando o caráter unitário do objeto social estudado". Através de análise da produção do jogo, audiência e demais variáveis que permeiam essa relação temos a seguinte questão que norteia esse artigo: Como a cultura de fãs pode modificar o método de produção de jogos de videogame e construir conteúdos colaborativos na contemporaneidade?

\section{Cultura da participação em jogos}

As reverberaçõesda comunicação do século XXI tendem a se ramificar por distintos meios. As incontáveis possibilidades desse novo espectro comunicativo ocasionaram diferentes formas de lidar com a informação, sobretudo em um cenário onde as noções de espaço virtual, mais ubíquos a cada dia, nos representa e dá voz, diferente de um passado em que o receptor de mensagens agia, sem escolha, com passividade (SANTAELLA, 2013).

A comunicação na cultura das redes, ainda que não seja a única forçamotriz dessa tendência de modernidade, promoveu guinadas nas avaliações de receptor passivo dos conteúdos que vêm de meios de comunicação de massa, ressignificando as possibilidades do receptor quanto à informação. Com comunidades virtuais se alicerçando progressivamente por meio de sociedades conectadas, um salto no que concerne aos processos de sociabilidade e compartilhamento de conhecimento fez-se vigente nessa esfera. Os mesmos corpos sociais, para Jenkins (2009), independem de instituições e governos que aclarem problemas e proveem as únicas vias de informação viáveis. Existe, nesse campo, uma cultura da participação, visto que, como audiência ativa e também possessora de informação, se estipula uma comunicação horizontal 
nesses ramos, onde todos retêm aptidão de compartilhamento.

Shirky atesta que "participar é agir como se sua presença importasse, como se, quando você vê ou ouve algo, sua resposta fizesse parte do evento" (SHIRKY, 2011, p. 25). Esse poder de voz, que tende a contentar a vontade intrínseca de participação, corrobora uma ideia de pertencimento, que além dafinalidade de comunicar, motiva que todas as pessoas em rede também concebam e mobilizem causas coletivas. Lévy revela que essa sintonia de informações partilhadas no mesmo ambiente promove o que ele conceitua como inteligência coletiva, que "é distribuída por toda parte, incessantemente valorizada, coordenada em tempo real, que resulta em uma mobilização efetiva das competências" (LÉVY, 1998, p. 28). Já Pires (2017) atesta que o presente contexto comunicacional em que estamos inseridos é apontado por ser participativo, coletivo, descentralizado,multimídiático e firme em princípios colaborativos. E, "os consumidores de informação, historicamente alocados na extremidade do processo comunicacional como receptores, agora também produzem conteúdo e exercem mais força sobre como e quando as informações circulam nas redes" (PIRES, 2017, p. 2).

Tendo em vistaque os videogames podem agir como uma forma de expressão cultural de nossa atualidade digital, é possível reiterar que essa inovação representada em dispositivos eletrônicos também permite que a cultura da participação esteja presente.

Sendo o universo lúdico expostopelos videogames um local em que conexões entre componentes visuais, textuais e multimidiáticos se determinam enquanto cruzam barreiras geográficas, há também circunstâncias de criação e compartilhamento, dentro e fora do meio dos jogos, reforçando a concepção de inteligência coletiva, fomentada pela interatividade dessa mídia.

Canclini afirma que consumir conteúdos culturais (proveniente ou não de jogos) resulta em um "conjunto de processos socioculturais nos quais se realiza a apropriação e o uso dos produtos", e, nesse uso é que "se constrói parte da racionalidade integrativa e comunicativa de uma sociedade" (CANCLINI,1993, p. 53).O fandom, nesse campo, é um dos 
centrais disseminadores dessa

sucessão.

Podendo

ser

formadotambém por usuários de videogames, ele auxilia para que as informações se apresentem em contínua multiplicação, seja na figura de fanfics, wikis, fóruns online ou ambiências virtuais. Elucidando esse panorama dentro do meio de jogos online, Gonçalves Jr. e Anchieta (2017, p. 83) alegam que:

\begin{abstract}
A compreensão do funcionamento da comunidade fã proporciona experiências muito intensas aos sujeitos. Para além do contato interpessoal, um conjunto de novas possibilidades se descortinam. Compartilhar sonhos, desejos e acima de tudo, um convívio, ainda que virtual, com pessoas que buscam se entreter e se dedicar com as mesmas coisas [...], cria uma atmosfera de fantasia e liberdade na qual se partilham as percepções do mundo em prol da construção de uma nova realidade, onde as fronteiras são determinadas pelos próprios participantes. Os sujeitos se atraem e desta relação de cumplicidade se materializam novas impressões das coisas e, consequentemente, novas memórias são trazidas para suas vidas cotidianas em forma de aprendizado e de poder de transformação de suas realidades).
\end{abstract}

Observa-se disso a produção de conteúdo elaborada por fãs da franquia de jogos de videogame Mass Effect. Palomino, em mapeamento da produtividade fã, ratifica que é possível encontrar mais de 15 mil fanfics na internet; obras audiovisuais viabilizadas noYouTube e em grupos de Facebook; áudio-dramatizações; vídeos musicais;fanartsememes, além de variados objetos replicáveis e trazidos pela própria dinâmica da comunidade (PALOMINO, 2015, p. 74).

\section{Breve considerações sobre fãs}

$\mathrm{Na}$ literatura dos estudos de fãs e fandom, encontramos variadas tentativas de definir e caracterizar tais grupos. Dayan considera os fãs a partir de quatro características: "o sentimento reflexivo de pertencer a uma comunidade imaginada, a capacidade de emitir opiniões ou pedidos narrativos, o aparecimento de uma sociabilidade direta, e a existência de uma dimensão de performance" (DAYAN, 2006 apud PARMEGIANNI, 2014, p. 28). Para Thompson (2014), o ato de ser fã envolve questões afetivas e atividades sociais entre pessoas. Klastrup (2010) destaca o envolvimento emocional e a identificação com uma obra, um artista etc.

Para Jenkins (2015), conceituar fandom requer englobá-lo considerando cinco dimensões de atividades. A primeira afirma que 0 
fandom está relacionado com "uma modalidade específica de recepção (Ibidem, p. 280), a qual envolve os processos de compartilhar, discutir com os outros, fazer releituras de textos etc." Já a segunda dimensão afirma o fandom a partir de "um conjunto específico de práticas críticas e interpretativas" (Ibidem, p. 280). Essa colocação diz respeito às atividades dos fãs com relação ao modo como seu objeto de adoração é explorado, a partir de certas práticas de leituras que são preferidas pela comunidade. Esse aspecto considera, por exemplo, que a comunidade de fãs de Beyond Good and Evil possui um modo particular de leitura, consumo e participação ao interagir entre si e com o jogo.

O terceiro ponto considera que o fandom "constitui uma base para o ativismo consumidor" (Ibidem, p. 280). Nesse tópico, Jenkins argumenta que boa parte dos fandoms se originam como resposta a uma suposta "impotência do consumidor diante das poderosas instituições de produção e circulação cultural" (JENKINS, 2015, p. 281). Devemos considerar, porém, que esse texto é originário de 1992. Assim, o autor explicita que os conglomerados de mídia não querem que os fãs façam exigências e que apenas aceitem o que Ihes é imposto. Portanto, Jenkins considera o fandom como uma comunidade não oficial, onde os participantes discutem desenvolvimentos e desdobramentos alternativos para a obra. As comunidades de fãs oficiais seriam aquelas que mantêm os interesses dos espectadores regulares e continuam gerando retorno (muitas vezes financeiro) para empresas. A diferença entre a publicação (1992) e o ano presente (2019) nos leva a repensar essa configuração. Recuero (apud JENKINS, 2016) coloca que as transformações tecnológicas, a internet, redes sociais e semelhantes funcionam como espaços e ambiências digitais onde os fandoms se reúnem e constroem sentidos. É importante refletir sobre essas mudanças e o impacto delas na relação entre fãs e conglomerados midiáticos, uma vez que o direcionamento fã e empresa não necessariamente é uma relação binária, onde o fandom sempre se apresenta como oposto aos interesses da empresa. Pelo contrário, a cultura dos fandoms atual, que tem como 
base a rede, pode ser pensada a partir da contribuição de seus participantes para com a obra, através de práticas de engajamento, as quais também veremos mais adiante. Recuero atesta o engajamento como "decorrência do envolvimento das pessoas entre si e com a marca como persona. É a construção de laços mais fortes, de capital social naquele espaço e naquela rede" (RECUERO, 2013, online).

A quarta dimensão dos fandoms para Jenkins (2015) está relacionada com a produção cultural. Diz respeito à arte que é criada pelos fãs e que "atendem interesses especializados da comunidade de fãs" (idem, p.281). É considerado que dentro do fandom não existe divisão definida entre artistas e consumidores: todos ali têm talentos em potencial que podem ser descobertos e explorados dentro daquele contexto de forma a enaltecer uma obra específica.Por fim, o quinto aspecto afirma 0 fandom como "comunidade social alternativa" (Ibidem, p. 282), em que certos valores "podem ser mais humanitários e democráticos do que os da sociedade mundana" (JENKINS, 2015, p. 282).
Dentre esses cinco tópicos definidos por Jenkins, damos destaque ao terceiro e ao quarto, uma vez que esse trabalho associa principalmente os níveis do engajamento entre os fãs a partir do consumo e das produções artísticas do mesmo em relação ao jogo. O terceiro, relacionado à ação fandom e suas produções de conteúdo, dão novos sentidos ao vínculo entre empresas e fãs, fazendo a manutenção de espaços sociais que contribuem para a disseminação da obra. Já o quarto, que iguala ao mesmo patamar toda e qualquer produção de conteúdo fã de uma obra, é considerado também um "portfólio" geral da cultura fandom de um segmento ou franquia.

\section{Beyond Good and Evil}

Vamos então ao jogo. Em 2003 - Ubisoft Montpellier Studios desenvolve o jogo Beyond Good and Evil, o primeiro trabalho da franquia homônima, visto como jogo dos gêneros aventura e ficção científica. 0 jogador encarna a repórter e fotógrafa Jade, uma das escassas personagens femininas em evidência que se retira 
do grupo hiper-sexualizado ${ }^{5}$. A ficção de Beyond Good and Evil guia o usuário para uma existência ficcional no ano 2435, em um futuro de tecnologias avançadas e diferentes raças alienígenas.

Vivendo noplanetaHyllis, em sítio longínquo do cosmos, Jade e a população do local são repetidamente atacadas por inimigos tiranos estelares. Ao mesmo tempo, o domínio militar ditatorial no planeta é incapaz de trazer segurança à população, o que levanta suspeitas de sua atuação, dando luz à entidade rebelde IRIS Network. O grupo revolucionário associa a tentativa frustrada de impedir os atacantes a uma conspiração do regime, visto que as tentativas de salvação frustrada sempre resultam em mais baixas do que o esperado. Jade, convocada pela resistência após a morte de um ente querido, passa a colaborar de forma contra-hegemônica, empregando sua competência com fotografia para reunir evidências que desmascarem a administração existente, provando a

\footnotetext{
${ }^{5}$ Reportagem a respeito da hiper-sexualização de personagens femininas em jogos eletrônicos:

http://www.mapinguanerd.com.br/oito-iconesde-um-breve-historico-das-personagens-

femininas-nos-games/ Acesso: 05 mar. 2019.
}

conspiração e salvandoa nação que vive em conjuntura de desgraça.

Lidando com temáticas que dialogam com falta de justiça, preconceito, contrabando humano, protagonismo da mulher e união pela mesma causa, Beyond Good and Evil teve triunfo na crítica, sendo nominado à premiação Game Developers Choice Awards ${ }^{6}$ como Jogo do Ano, no ano posterior ao lançamento. Contudo, resultou em fiasco comercial, que levou o título ao esquecimento do grande público, ainda que posteriormente, devido a seu teor, tenha obtido a condição de "cult".

Meia década após a difusão de Beyond Good and Evil, em 2008, a Ubisoft divulgou em sua convenção anual para a imprensa ${ }^{7}$ um trailer do que viria a ser a continuação da obra, Beyond Good and Evil 2. Os fãs, então, amadureciam cotidianamente o entusiasmo em espaços online tais como wikis, fóruns e coletividades cibernéticas (figura 1). Não obstante,

\footnotetext{
${ }^{6}$ Convenção que garante premiações aos melhores jogos lançados. Uma espécie de "Oscar dos Videogames": http://www.gamechoiceawards.com/archive/gd ca_4th.html Acesso: 08 mar. 2019.

${ }^{7}$ Convenção da Ubisoft para a imprensa: http://www.ubidays.com/ Acesso: 10 mar. 2019.
} 
com múltiplas conferências posteriores com o passar do tempo e sem apresentar notícias acerca da obra, os apreciadores da franquia desacreditaram no lançamento. Entretempo, somente nove anos após o trailer passado, durante a E3 2017, retornos emergiram. Em reunião com declarações e reconhecimento do diretor criativo e diretora de narrativas da Ubisoft ${ }^{8}$, a centelha do fandom foi reanimada com um novo trailer $\mathrm{e}$ moveu novamente a massa de fãs da franquia.

\footnotetext{
${ }^{8}$ Demonstração de Beyond Good and Evil 2 na E3 com Michel Ancel (diretor criativo) e Gabrielle Shrager (diretora de narrativas): https://www.youtube.com/watch?v=1_jCaoJsjO k\&t=239s Acesso: 10 mar. 2019.
} 
Figura 1: Print-Screen da seção de comentários do YouTube ${ }^{9}$ em trailer de 2008.

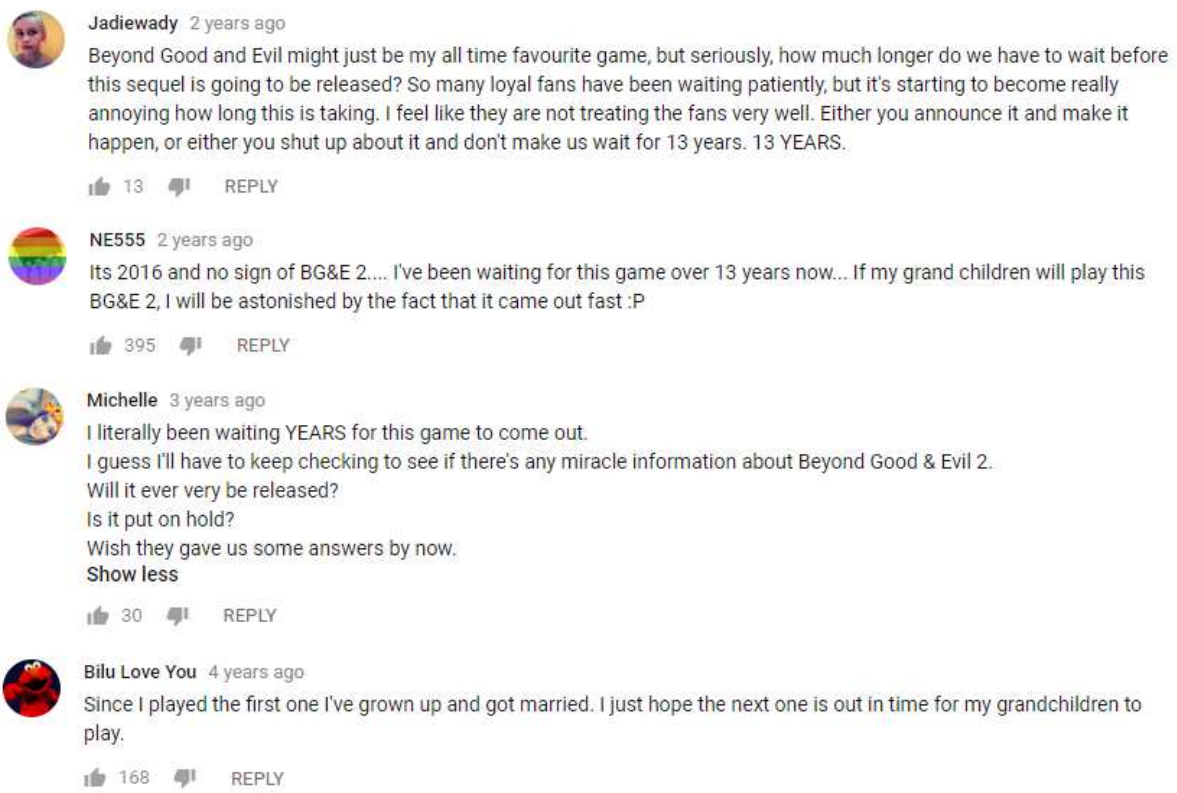

Fonte: YouTube

\footnotetext{
${ }^{9}$ Trailer de Beyond Good and Evil 2, em 2008: https://www.youtube.com/watch?v=vkCXE115MVI Acesso: 10 mar. 2019.
} 
Ainda na E3 2017, foi anunciado que o próximo títulose estruturaria em linha temporal antes dos ocorridos de seu predecessor, harmonizando um universo com junção de etnias e culturas, povoado por homens e mestiços de animais nas peculiaridades de um século 24 ficcional. Nessa instância simulada, corporações geram pessoas híbridas e os subjugam à escravidão, para excursões de colonizaçãode planetas. Em oposição à injustiça, um grupo de resistência combate pela autonomia.

Com as minúcias apresentadas pelo trailer e pela convenção, as esferas virtuais retornam ao movimento de engajamento nos fóruns, partilhando outra vez ocasiões e interesses comunitários que no passado propiciaram a harmonia entre esses mesmos conjuntos. Tópicos que abordam os melhores momentos que usuários gozaram em Beyond Good and Evil são recorrentes no fórum oficial da Ubisoft $^{10}$, assim como debates acerca da trilha sonora, o design do jogo e demais experiências que enaltecem a sociabilidade por meio de perfis que integram o online e off-line.

A E3 2017 também contou com a apresentação de uma nova ferramenta de reforço à construção do novo jogo, o Space Monkey Program. O projeto evidencia uma plataforma colaborativa comum aos usuários e desenvolvedores da Ubisoft, em que o conteúdo produzido pode ser elaborado de forma síncrona, isto é, contando com participação ativa dos entusiastas da franquia. Para adentrar à iniciativa, jogadores precisam conectar-se ao site oficial ${ }^{11}$ de Beyond Good and Evil 2, registrar uma conta e usufruir de pesquisas de conteúdo, interações em comunidades virtuais oficiais e notícias em primeira mão.

\footnotetext{
${ }^{10}$ Fórum oficial de Beyond Good and Evil em tópicos de discussões sobre o jogo: https://forums.ubi.com/showthread.php/169866 9-Strong-Female-Characters Acesso: 10 mar. 2019.

${ }^{11}$ Site oficial do Space MonkeyProgram: https://Beyond Good and Evil.ubisoft.com/enus/spacemonkeyprogram Acesso: 10 mar. 2019.
} 
Figura 2: Aspectos sociais do fandom no fórum oficial do jogo ${ }^{12}$.

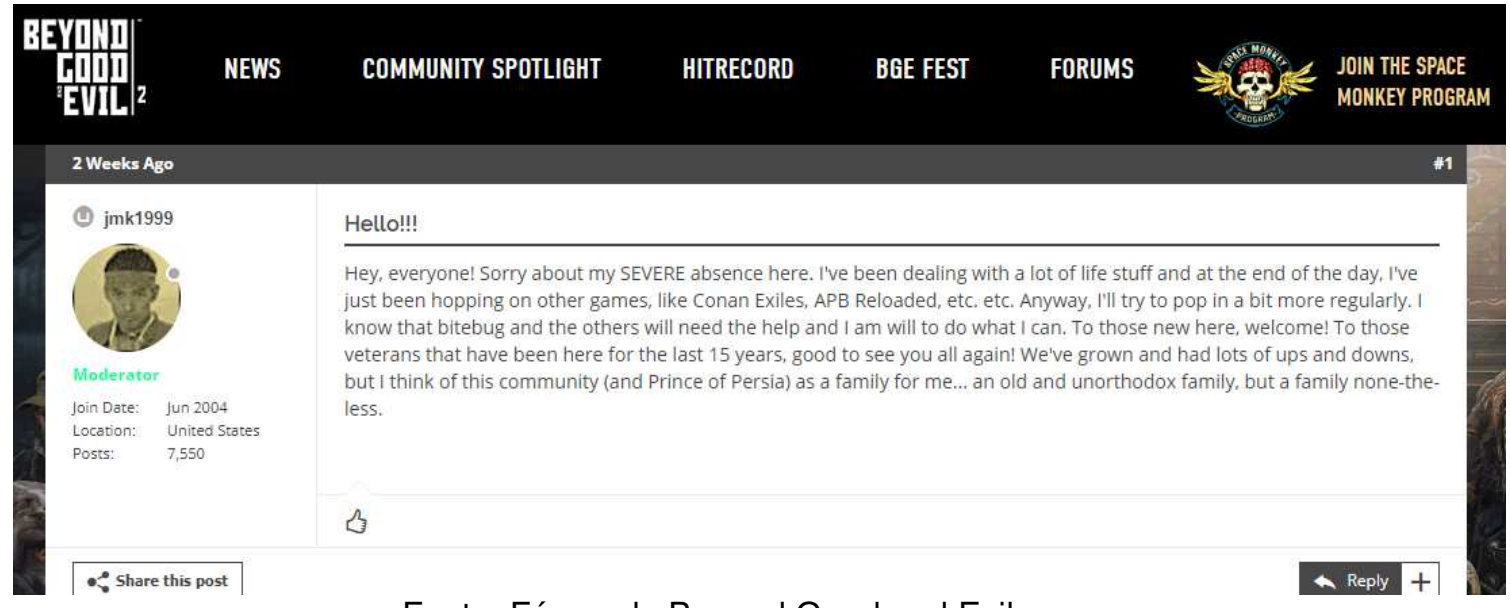

Fonte: Fórum de Beyond Good and Evil

12 O fórum oficial de Beyond Good and Evil e questões de sociabilidade:

https://forums.ubi.com/showthread.php/1894569-Hello!!! Acesso em: 10 mar. 2019. 
Em 2018, também durante a E3,foram divulgadas mais notícias sobre o novo título, e mais um trailer apresentando personagens. $O$ jogo (online e cooperativo entre jogadores) se passa, até então,numa cidadela digitale algumas mecânicas de jogo da sequência também foram difundidos ${ }^{13}$. A plataforma de colaboração, agora acessível para usuários de todos os continentes, contava com exemplos da gama de possibilidades de criação de conteúdo, como artes e audiovisual, que aprimorado pelos usuários terão presença no jogo. Houve acordo entre a Ubisoft e a instituição parceira HITRECORD, que assegurou que o

\footnotetext{
${ }^{13}$ Vídeo da conferência da Ubisoft na E3 2018: https://www.youtube.com/watch?v=PeK9CP84 Qlk\&t=465s Acesso: 10 mar. 2019.
}

material produzido por fãs seria firmado no título e nas narrativas dos jogadores ao percorrerem as ambiências digitais presentes (figura 3). Mediando o processo, a parceira administradesde o ciclo que divulga demandas (em formato de briefing e vídeo) até a instância de pagamento pela produção fã. Ademais, o projetose reafirma como uma plataforma aberta que supre a comunidade colaborativa, considerando sua finalidade ${ }^{14}$. Apesar da possibilidade de criar conteúdo do princípio, é permitido, inclusive, colaborar a partir de matrizes já otimizadas por outros por meio de edição.

\footnotetext{
${ }^{14}$ Página da HITRECORD referenciando o dinamismo dos projetos colaborativos:https://hitrecord.org/help Acesso: 10 mar. 2019.
} 
Figura 3: Ubisoft na E3 2018.

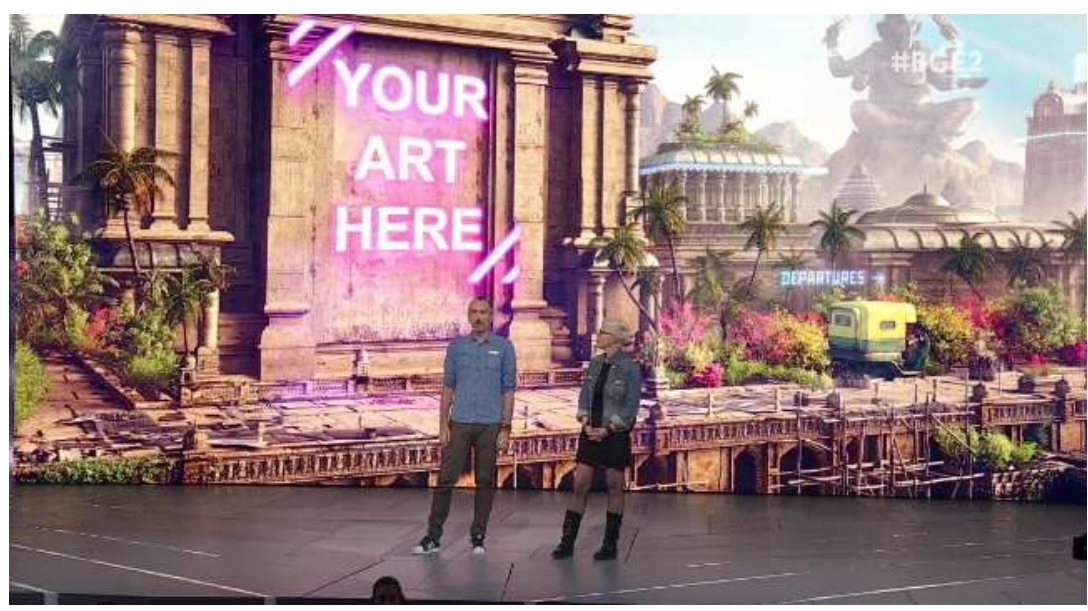

Fonte: Site Koopatv.org

No programa HITRECORD ${ }^{15}$ são expostas demandas dos produtores do jogo,que os usuários verificam e dão início ao processo criativo caso tenham interesse. Os administradores reproduzem briefings com orientações e delimitações do objetivo almejado, logo, com essa divulgação, a incumbência se instaura. A plataforma não promove uma competição direta aos moldes de um concurso. Entretanto, oportuniza e põe em evidência o estímulo colaborativo de produção em grupo. Dentro dos projetos musicais, há Shankara, uma música a ser tocada em ambiências digitais do jogo que evoca a ideia de

\footnotetext{
${ }^{15}$ Página oficial dos projetos colaborativos abertos em Beyond Good and Evil 2: https://hitrecord.org/productions/3502858 Acesso: 10 mar. 2019.
}

devocional com mantras. Com mais de 60 contribuições de músicos, produtores, vocalistas e compositores, a iniciativa é explorada de diferentes formas. Há a proposta de efeitos adicionais de voz pelo usuário pablojgarmon, letras compostas por Aradhyeaxat, dublagem no idioma híndi de trechos da música por Ananya Dixit e até mesmo a adição do instrumento aborígene didjeridu por Samuel Stokes ${ }^{16}$, dentre muitos outros.

Artes gráficas também contam com seu espaço de produção na plataforma. Um exemplo é a iniciativa Anti-Hybrid Propaganda, que se baseia em arte urbana, anúncios, cartazes e outras expressões

\footnotetext{
${ }^{16}$ Página do projeto Shankara:

https://hitrecord.org/projects/3550096/interests/ all. Acesso: 13 mar. 2019.
} 
COSTA, Caio Túlio Pereira da; MENESES, Bruna Maria de; SILVA, Eduardo Duarte Gomes da. Videogames e cultura colaborativa: a audiência como produtora de conteúdo em Beyond Good and Evil 2. PragMATIZES -

Revista Latino-Americana de Estudos em Cultura, Niterói/RJ, Ano 10, n. 19 , p. 118-140, set. 2020 .

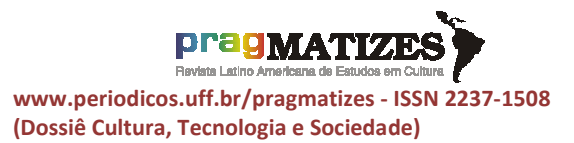

(Dossiê Cultura, Tecnologia e Sociedade)

referentes à opinião de certos disponibilizadas para conferência e personagens que comporão o quadro modificação por qualquer usuário, com do jogo. As colaborações, a HITRECORD assegurando créditos aproximadamente 1,3 mil, são e legalidades da imagem (figura 4).

Figura 4: Interface do projeto Anti-Hybrid Propaganda ${ }^{17}$.

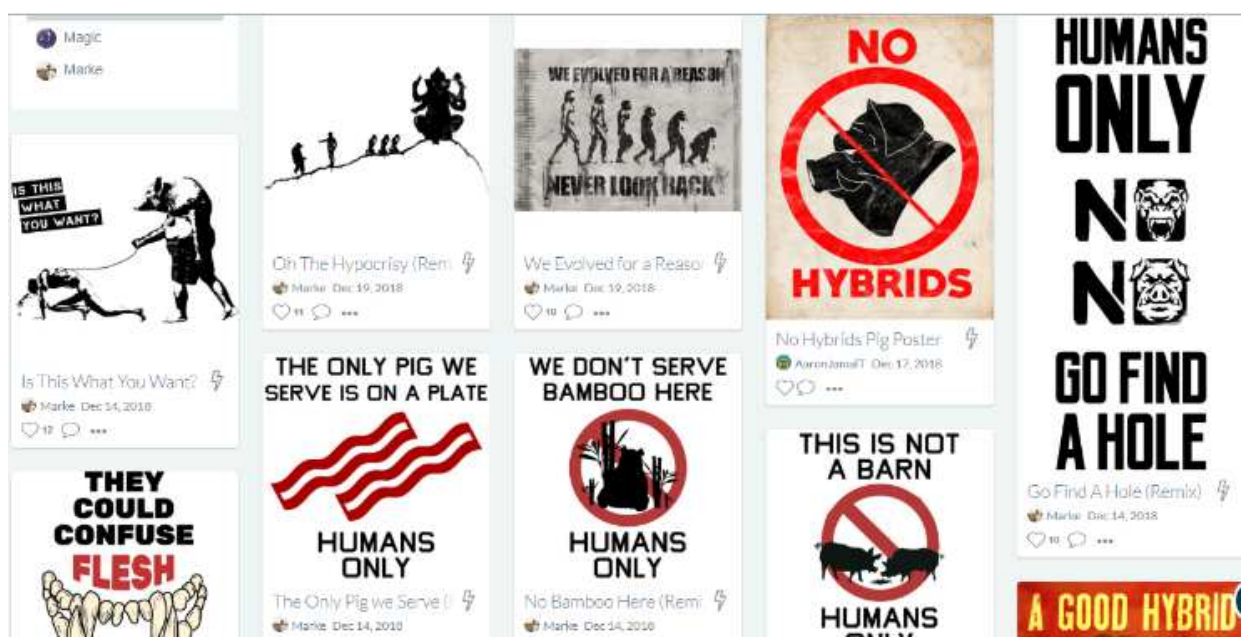

Fonte: HITRECORD

${ }^{17}$ Página do projeto colaborativo de Anti-Hybrid Propaganda: https://hitrecord.org/projects/3505007/interests/all. Acessom: 13 mar. 2019. 
Além das parcerias citadas, há, conjuntamente, a realização de mecânicas de puzzles (quebracabeças), enigmas e padrões de imagem a partir de design de jogos. Segundo o vídeo de instruções e briefing do projeto Geoglyph Puzzles ${ }^{18}$, o jogo conta com desafios para jogadores desvendarem a partir de marcações gráficas no solo das ambiências. Desenhos gigantes que só podem ser vistos como um todo do alto vão estar presentes, onde a criatividade dos produtores rege as opções disponíveis. Uma formação rochosa que simula linhas e geoglifos de Nazca, no Peru, por exemplo, assim como uma seta apontando para tesouros ou templos religiosos escondidos podem trazer à narrativa um detalhamento que facilita a imersão e projeção-identificação com a história do jogo (figura 5).

\footnotetext{
${ }^{18}$ Projeto Geoglyph Puzzles:

https://hitrecord.org/projects/3505079/highlight s Acesso: 13 mar. 2019.
}

Para além das composições em colaboração, a Ubisoft foca nas atividades dos admiradores que reforçam a franquia desde sua distribuição. Pode-se verificar no site oficial uma aba de nome Community Spotlight (Holofote na Comunidade, em livre tradução), que abrange perfis que apoiam o universo do jogo com elaboração de conteúdo inédito, difundindo conhecimentos, e até mesmo com produções audiovisuais. Esse modo de exposição de engajamento traz holofotes para 0 fandom, evidenciando produtores de conteúdo que antes eram desconhecidos e são significativos para a franquia(figura 6). 
Figura 5: Trecho do vídeo explicativo do projeto de conteúdo Geoglyph Puzzles e proposta do usuário Jofwa com a ideia de criar um templo/cidade em uma ilha no formato de tartaruga marinha ${ }^{19}$.

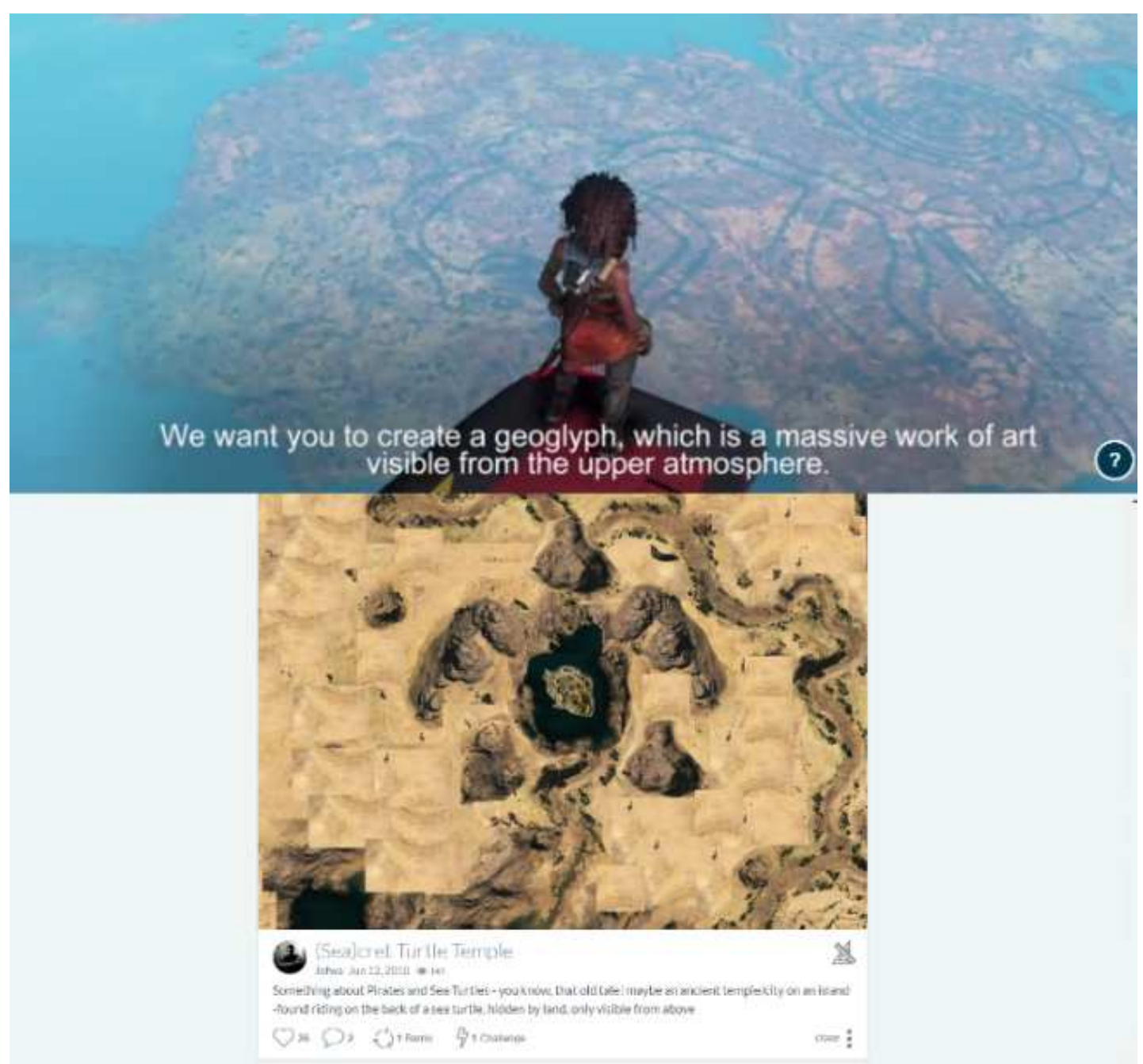

Fonte: HITRECORD

${ }^{19}$ Proposta do usuário Jofwa: https://hitrecord.org/records/3518557/comments Acesso: 13 mar. 2019. 
Mesmo com as produções colaborativas acontecendo, a data de distribuição do jogo ainda não foi anunciada. Todavia, na cidade francesa de Montpellier, a Ubisoft sediará o BGE Fest ${ }^{20}$, uma convenção com foco em Beyond Good and Evil que busca ampliar os elos e promover sociabilidade entre jogadores, desenvolvedores e mentes criativas. Os responsáveis pelo jogo acompanham os trabalhos colaborativos e costumam trazer feedbacks e atualizações esporádicas através de vídeos ao vivo, os Space Monkey Reports, na plataforma YouTube. Essa transparência e comunicação horizontal promove comunicabilidade, regulando ideias durante as "lives" 21 ". A partir das formas de engajamento oferecidas $e$ levantadas anteriormente, uma tabela foi criada para apresentar de maneira sucinta as diferentes possibilidades de interação entre fãs e empresa. Foram acrescentados, também, outros exemplos de produções do fandom presentes nas plataformas.
${ }^{20}$ Mais informações do BGE Fest: https://Beyond Good and Evil.ubisoft.com/enus/bgefest Acesso: 13 mar. 2019.

\footnotetext{
${ }^{21}$ Space MonkeyReport: https://www.youtube.com/watch?v=tGFi3_NTD8Acesso: 11 mar. 2019.
} 
Figura 6: Fandomno Community Spotlight ${ }^{22}$.

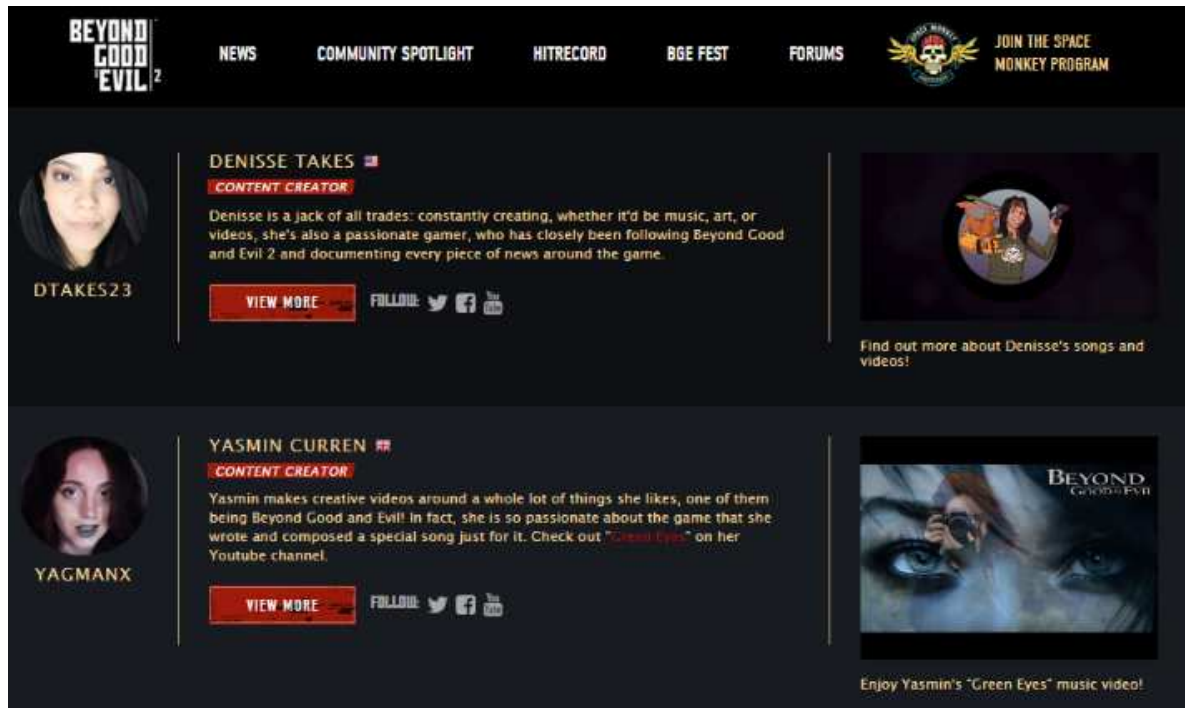

Fonte: Site de Beyond Good and Evil

Tabela 1 - Possibilidades de Interação Fandom em BGE2

\begin{tabular}{|c|c|c|c|}
\hline NOME & DESCRIÇÃO & $\begin{array}{l}\text { CONTRIBUIÇÃO DA } \\
\text { AUDIÊNCIA }\end{array}$ & EXEMPLOS \\
\hline Fórum oficial & $\begin{array}{l}\text { Evidencia a } \\
\text { sociabilidade dos fãs } \\
\text { no que diz respeito } \\
\text { ao jogo. }\end{array}$ & $\begin{array}{l}\text { Melhores momentos: } \\
\text { - Trilha Sonora; } \\
\text { - Design; } \\
\text { - Experiências. }\end{array}$ & $\begin{array}{l}\text { - Mapeamento de notícias sobre o } \\
\text { lançamento da franquia, feito de } \\
\text { fãs para fãs, em arquivos } \\
\text { disponibilizados no fórum. } \\
\text { - Ideias para criação de } \\
\text { personagens, históricos e } \\
\text { narrativas. }\end{array}$ \\
\hline $\begin{array}{l}\text { Space } \\
\text { MonkeyProgram }\end{array}$ & $\begin{array}{l}\text { Plataforma } \\
\text { colaborativa entre os } \\
\text { criadores do jogo e a } \\
\text { audiência. }\end{array}$ & $\begin{array}{l}\text { - Ideias; } \\
\text { - Vídeos; } \\
\text { - Artes; } \\
\text { - Conceitos. }\end{array}$ & $\begin{array}{l}\text { - Sugestão de dubladores, de } \\
\text { criação de personagens (raças } \\
\text { específicas), corridas com veículos } \\
\text { diferenciados. }\end{array}$ \\
\hline HITRECORD ${ }^{23}$ & $\begin{array}{l}\text { Comunidade criativa } \\
\text { online que faz arte } \\
\text { de maneira } \\
\text { colaborativa. } \\
\text { Apresenta outros } \\
\text { projetos além de } \\
\text { Beyond Good and } \\
\text { Evil. }\end{array}$ & $\begin{array}{l}\text { - Música ( } 24 \text { projetos } \\
\text { abertos); } \\
\text {-Visual (5 projetos } \\
\text { abertos); } \\
\text { - Outros ( } 2 \text { projetos } \\
\text { abertos). }\end{array}$ & $\begin{array}{l}\text { - Músicas futuristas, temas para } \\
\text { piratas, rock, músicas para } \\
\text { meditação e espiritualidade etc. } \\
\text { - Design de arte, pôsteres, } \\
\text { propagandas temáticas, murais } \\
\text { religiosos, símbolos etc. } \\
\text { - Quebra-cabeças; } \\
\text { - Áudios para a rádio presente no } \\
\text { jogo (spots, gravações, etc.). }\end{array}$ \\
\hline
\end{tabular}

${ }^{22}$ Community Spotlight: https://BeyondGoodandEvil.ubisoft.com/en-us/spotlight. Acesso: 11 mar. 2019.

${ }^{23}$ Dados de 25 de outubro de 2019. 


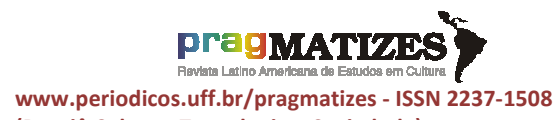

(Dossiê Cultura, Tecnologia e Sociedade)

\section{Considerações finais}

A comunidade de Beyond Good and Evil apresenta uma combinação de todas essas nuances: o jogador é também aquele que contribui ativamente para a produção do jogo. Essa contribuição se dá, dentre outros exemplos, a partir de ideias, sugestões, produção de material artísticoetc. - embasadas na recepção e interpretações particulares que a comunidade faz da obra.

Observando a tabela anterior, retomamos algumas das características de fandom apresentadas por Jenkins (op. cit.) e citadas previamente neste trabalho, sendo possível identificá-las de maneira mais prática. Dentre as dimensões consideradas, temos 0 fandom envolvido em um modo específico de recepção, que dá novo significado às possibilidades de produção, além de incorporar práticas críticas e interpretativas. Outros dois pontos são o papel do ativismo do consumidor, elencando suas produções e liberdade como representatividade, e a relevância da produção cultural artística dos fãs, compondo de forma macro o universo considerado pela comunidade (2015).
O jogador será consumidor não apenas do produto final, mas, ao fazer parte do processo de criação, ele se vê mais próximo do seu objeto de adoração - o jogo de videogame -, criando vínculos mais fortes não apenas com o produto, mas também com outros fãs a partir das trocas de experiências, ideias e valores realizadas naquele meio. Os produtores tendem a conseguir respostas mais diretas dos fãs. A proximidade pode permitir que seu trabalho tenha resultados mais bem aceitos na versão final do jogo. Se a cultura da participação toca em inúmeros juízos, os jogos não estariam fora desse espectro. A ideia de inteligência coletiva se afirma em distintos formatos, resultando, também, em audiências ativas, aprimorando a sociedade conectivista em que vivemos. Representatividade, pertencimento e a descentralização de hierarquias marcam esse avanço, transformando 0 ato de jogar em termos de experiência.

A partir dessas considerações, entende-se que a dinâmica apresentada por Beyond Good and Evil 2 proporciona inovação para os envolvidos, além de destacar a 
COSTA, Caio Túlio Pereira da; MENESES, Bruna Maria de; SILVA, Eduardo Duarte Gomes da. Videogames e cultura colaborativa: a audiência como produtora de conteúdo em Beyond Good and Evil 2. PragMATIZES -

Revista Latino-Americana de Estudos em Cultura, Niterói/RJ, Ano 10, n. 19 , p. 118-140, set. 2020.

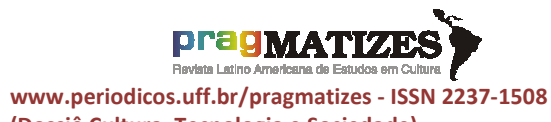

(Dossiê Cultura, Tecnologia e Sociedade) importância da internet para que essas interações funcionem de forma satisfatória e que o papel de agente multimídia dos fãs tenha potencialidades para ser reforçado. Naturalmente que tudo o que aqui fazemos é estudar e analisar um processo que ainda está em andamento. $O$ resultado que vai emergir dessa rede cooperativa ainda vamos conhecer com o lançamento do jogo, entretanto, o processo já demonstra ser muito rica a cultura cooperativa de um fandom na realização de um produto de usufruto comum a todos, fãs ou não.

\section{Referências bibliográficas:}

BAILÉN, Amparo Huertas. La Audiencia Investigada. Barcelona: Gedisa, 2009.

CAJAZEIRA, P. E. S. L.; SOUZA, J. J. G. de Interatividade digital, audiência e webdocumentários. Doc On-Line: Revista Digital de Cinema Documentário, n. 18, 2015.

CANCLINI, Nestór García. El consumo cultural y suestudioenMexico: una propuesta teórica. Mexico: CNCA, 1993.

CANCLINI, Nestór García. Leitores, Espectadores e Internautas. São Paulo: lluminuras, 2007.

GONÇALVES JÚNIOR, R. J.; ANCHIETA, W. Comunidade fandom de roleplay em World of Warcraft no
Brasil: suas narrativas, performances e representações. In: Seminário de Alunos de Pós-Graduação em Comunicação. 2017, Rio de Janeiro. Anais. Rio de Janeiro: Compós, 2017.

GOODE, W.J.; HATT, P.K. Métodos em pesquisa social. São Paulo: Nacional, 1979.

GRAY, J.; SANDVOSS, C.; HARRINGTON, C. L. Fandom: Identities and Communities in a Mediated World. New York: New York University Press, 2017. Disponível em: https://books.google.com.br/books/ab out/Fandom Second Edition.html?id $=$ cflAQAACAAJ\&redir_esc $=y$.

Acesso: 03 mar. 2019.

JENKINS, H. Cultura da convergência. São Paulo: Aleph, 2009.

JENKINS, $\mathrm{H}$. Fandom, participatoryculture, and Web 2.0. - A Syllabus. Disponível em: http://henryjenkins.org/blog/2010/01/fa ndom_participatory_culture_a.html. Acesso: 03 mar. 2019.

JENKINS, H. Invasores do texto: fãs e cultura participativa. Nova Iguaçu, RJ: Marsupial, 2015.

KLASTRUP, L. Publics for a day? The Affective "Audiences" on Facebook. Dinamarca: Universityof Copenhagen, 2010.

LÉVY, P. A inteligência coletiva. São Paulo: Edições Loyola, 1998.

PALOMINI, P. T. We will hold the line: o fandom como forma de participação dos fãs no desenvolvimento do universo transmidiático do jogo masseffect. São Carlos: Repositório Institucional Ufscar, 2015. 
PARMEGGIANI, B. Fãs e sites de redes sociais: um estudo de caso da participação no programa the voice. Revista GEMInIS, [S.I.], v. 5, n. 2, p. 23-46, jul. 2014. Disponível em: http://www.revistageminis.ufscar.br/in dex.php/geminis/article/view/188.

Acesso: 14 mar. 2019.

PIRES, R. V. Jogando com a mente coletiva: mecânicas colaborativas em videogames e literacia digital em tempos de compartilhamento.In: SBGames. 2017, Curitiba. Proceedings. Curitiba: Sbc, 2017.

RECUERO, R. Engajamento $x$ Audiência no Facebook: uma breve discussão. Pelotas: 2013. Disponível em:

http://www.raquelrecuero.com/arquiv os/2013/03/engajamento-x-

audienciano-facebook.html. Acesso: 14 mar. 2019.

RECUERO, R. Problematizando Fãs e Fanfictions 20 anos depois.In: JENKINS, Henry. Invasores do texto: fãs e cultura participativa. Nova Iguaçu, RJ: Marsupial, 2015.

SANTAELLA, L. Comunicação Ubíqua: Repercussões na Cultura e na Educação. São Paulo: Paulus, 2013.

SHIRKY, C. A Cultura da Participação: Criatividade e Generosidade no Mundo Conectado. Rio de Janeiro: Zahar, 2011.

YIN, R. K. Estudo de caso: planejamento e métodos. Porto Alegre: Bookman, 2010. 